\title{
The Judgement of Architecture
}

\author{
Daniel Payot \\ Translation by Tim Adams
}

The source for this translation is Daniel Payot, Le jugement de l'architecture, Le Portique: Revue de philosophie et de sciences humaines: 3 (1999). Many thanks to Dr Trudy Agar-Mendousse for pointing out many areas where improvements could be made to an earlier draft of this translation. Naturally any errors that remain are entirely my own. - Trans.
One of the difficulties facing criticism is that it must always connect, and it has to do this precisely where the dimension of liaison is no longer in evidence. Perhaps, this is why the problems facing criticism can reveal not only the difficulties, but also the opportunities inherent in modernity as a whole and not just theoretical modernity.

We know that to criticize is to examine: krinein, to judge, to match a predicate to a subject, a quality to a substance, etc. However, criticism is also a gestural activity; it takes hold of an object, looks for values and meanings, and establishes close and distant connections between the two. A critique of criticism should always recognize the fact that criticism is never simply concerned with the presence of a thing or a work; nor is it ever simply a critic judging, or a penetrating subjectivity, but it is, above all, a gesture that the critic makes with regard to the thing or the work, or what the thing or work invites them to make. Therefore, the problem is: where does the possibility for the liaisons that the critic must make come from? Where can the possibility for legitimizing the critic's gesture be found?

And here a kind of withdrawal takes place: we need to attach the activity of judgement to "something" that can, itself, attach a quality to an object; but to what is this gesture connected, or what connects to it? The critic acts in the name of a transcendental authorization that they can never make fully explicit, about which they can even be totally unaware, but which, nevertheless, is the basis for the gesture - rendering it possible, inaugurating it and giving it meaning. The multiplicity of liaisons produced by the act of judgement is preceded by: "it is possible to connect" (most often unspoken); or, indeed, by a, "you have the right to connect", and perhaps even more fundamentally, by a usually implicit, "you must connect". These are the in-junctions that open and render the critical junctions effective, but which generally remain exterior (except when critical discourse questions the precise reasoning behind criticism, its foundations and its authority; in other words when it exceeds its immediate exercise and concerns itself with its own limits).

Therefore, for example, when criticism talks about things, works of art, or architecture, it is also speaking about itself, in the sense that it responds to the problem of its own legitimacy. Since it speaks and criticizes at the same time, it must have solved the problem of what gives it the authority to judge: criticism, in so far as it criticizes, must always make its judgements as if the validity (the predication) needed to do so was already established elsewhere.

Perhaps, this is why there is really no criticism that is absolutely negative: even when something is linked to a negative attribute, even when the predication is pejorative, criticism, as such, is inexorably positive, at least in regard to it- 
self; it must have already assured itself of its own right to judge. Therefore, it seems possible to support the thesis of an essential and constitutive positivity of all criticism.

This hypothesis seems completely at odds with what we so often hear today: that judgement has become so difficult that we may have even lost this faculty altogether; that art criticism, and architectural criticism in particular, have become decadent, mute and little more than pointless gossip: our critics no longer teach us anything. Obviously, these assessments seem to contradict the tentative suggestion made above: if criticism was so positive, it should always be able to make judgements without too much difficulty.

However, perhaps there is a way of answering this dilemma that will at first seem provocative, but may nonetheless lead to a solution. It would be to reply that the problem of criticism today - the biggest problem it faces, besides the too easy and too frequent diagnosis of "decadence" - finds its cause in the very positivity that constitutes criticism: it is because criticism cannot avoid being positive that it is so poorly considered today. If the critic is indeed more hesitant, timid, powerless and mute, it is not because they have run out of things to say about works of art and architecture. On the contrary, in general, we know much more about them now than during those earlier periods of history when criticism seemed to flourish and have an immediate impact; nor is it due to the application, to particular cases that interest it, of the models, rules, canons and laws upon which criticism was founded. Rather, it is because criticism itself no longer knows what meanings to give the positivity that constitutes it, and which can only be avoided by denying any role for the critic, which thereafter can never be filled. The problem, then, would be the inalienable remainder and burden of positivity, whose persistence becomes more obvious the less confident criticism becomes of finding external criteria able to guarantee its legitimacy in a "transcendent" normativity.

In a certain sense, this difficulty is a consequence of "reflective" judgement. Kant defined it in these terms:

Judgement in general is the faculty of thinking the particular as contained under the universal. If the universal (the rule, principle, or law) is given, then the judgement which subsumes the particular under it is determinant... If, however, only the particular is given and the universal has to be found for it, then the judgement is simply reflective (Kant, 1952: 18).

Because it must formulate itself prior to any concept of the beautiful being given, aesthetic judgement can only be reflective; it isnot preceded by the presentation of a principle by which it would then only need to select particular things to order to declare them beautiful. The exercise of reflective judgement is immediately confronted by an absence, by a primary non-given. It has to evaluate while lacking the measure for evaluation; it is unable to refer to a previous principle that, alone, would guarantee and give assurance to judgement.

Nevertheless, this could be considered to be not the most difficult problem, since despite the irreducible distance opened up between the need to formulate a judgement and the failure to present the principle behind its formulation, 
judgement can still get by with analogies and substitutions, and the use of the "as if", with reflection to be precise. According to Kant, judgement does not collapse when it fails to present its principle of evaluation: instead, it discovers the means for its survival; it presents things as particular cases of a general law, by means of which it becomes possible to make a judgement legitimate and universal (although not objective). Certainly, determinant judgement, since it refers to previously applied rules, always appears more certain - and is in deed "objective": that is to say, it does know something about its object, which is not the case for aesthetic judgement, which, being "subjective", translates the state of the subjectivity that judges - and this is not a property of its object. However, this apparent handicap creates the possibility that judgement evaluates itself, a possibility not offered by the determinant judgement, since its exercise of judgement is ordered according to the application of laws or norms. Reflective judgement is subjected to the test of having to present itself to itself (hence the term "reflective"), a test that places it in a moment of peril (the critical moment where the evaluation evaluates itself and the examiner is summoned to the examination of their right to examine), though, according to Kant, it emerges from this test the victor. In the end, its legitimacy is even more strongly established, since it was not given in advance and since it had to win this for itself. How does this work?

In Kantian terms, the answer to this question is: by means of "common sense" as the following two extracts will define:

Were judgements of taste (like cognitive judgements) in possession of a definite objective principle, then one who in his judgement followed such a principle would claim unconditioned necessity for it. Again, were they devoid of any principle, as are those of the mere taste of sense, then no thought of any necessity on their part would enter one's head. Therefore they must have a subjective principle, and one which determines what pleases or displeases, by means of feeling only and not through concepts, but yet with universal validity (Kant, 1952: 82, § 20).

Now, for this purpose, experience cannot be made the ground of this common sense, for the latter is invoked to justify judgements containing an 'ought' (ein Sollen). The assertion is not that every one will fall in with our judgement, but rather that every one ought to agree with it. Here I put forward my judgement of taste as an example of the judgement of common sense, and attribute to it on that account exemplary validity. Hence common sense is a mere ideal norm. With this as presupposition, a judgement that accords with it, as well as the delight in an Object expressed in that judgement, is rightly converted into a rule for every one. For the principle, while it is only subjective, being yet assumed as subjective universal (a necessary idea for every one), could, in what concerns the consensus of different judging Subjects, demand universal assent like an objective principle, provided we were assured of our subsumption under it being correct (Kant, 1952: 84-85, § 22). ${ }^{2}$ 
The expression, "a subjective principle", perhaps summarizes most of the problems usually formulated about criticism. Unless one proposes, like Baudelaire, that "to be in focus, in other words to justify itself, criticism must be partial, passionate, political, that is to say it must adopt an exclusive point of view" (Baudelaire, 1992: 50), ${ }^{3}$ it seems, in fact, inevitable to agree with Kant that subjectivity is, in the act of judgement, preceded by a principle of determination. If that was not the case, the enunciated critique could not claim any "necessity", it would only be the expression of an immediate sensible state and, therefore, entirely individualistic. Criticism, then, would consist entirely of a discursively enunciated set of personal feelings, emotions and affects without any pretension to universality. Kant suggests this would not be criticism: the statement would not be predicated and the proposition would not be, strictly speaking, a judgement. However, since the enunciating subjectivity is not completely confined to the immediacy of its affects and confronts other dimensions, it finds the resources for a gesture of attribution and determination. It is because the subjectivity that judges refers to such a principle that the judgement can take the form of a duty or a requirement. Because it is no longer simply the expression of a particular subject, it can claim the universality of the impersonal, the neutrality or generality of a principle.

Now the principle in this case cannot be objective: determination in aesthetic matters cannot be made by a concept. The principle dimension that precedes judgement, that informs it and gives it its predicative status is not the type of liaison that constitutes the unity of a given diversity prior to the encounter with the object of judgement: aesthetic judgement is not a knowledge judgement. Furthermore, the principle does not belong to an order that would be exterior to subjectivity: it is only ever located in it. How, then, can it still be a principle? Does not its subjective constitution remove all pretension to legislate from it? What, in fact, is its necessity if it cannot be the "unconditioned necessity" of determinant judgements? And in what sense can it be universal?

The main thrust of Kant's argument consists of sustaining the idea of a dimension which must be subjective (since it is a matter of relating to something which does not have any concept, and the method of this relation is no longer simply feeling), but which, nevertheless, allows for a determination, "with universal validity" being "assumed as subjective universal" (otherwise we cannot maintain the proposition that, properly speaking, they are judgements when we do not have any concept for them). It is, therefore, necessary that this universality be found in the only domain established here: in other words in feeling, sensation and subjectivity. The "common sense" is a communication of feelings that, instead of leaving each person in the particularity of their sensible experience, constitutes an "ideal norm" that each person can claim, and in the name of which they "could, in what concerns the consensus of different judging Subjects, demand universal assent like an objective principle."

Despite these explanations, it is still quite difficult to put aside the scepticism we no doubt have about the sense of uselessness we feel whenever "taste and preferences" are discussed. Today, the predominant subjectivism is largely a form of nihilism: the right to feel and to like whatever one wants is certainly recognized, but, often, this comes at the cost of rejecting any principle whatsoever, which is to say any judgement as well. That is why it is important not to stop with the Kantian
3. To do it justice, let us quote the end of the sentence, the further examination of which would lead to other considerations: "...it must adopt an exclusive point of view, provided always the one adopted opens up the widest horizons." 
affirmations about the existence of such a principle, or such an ideal norm; it is necessary to rediscover Kant's explanation of the mechanism of common sense:

For where any one is conscious that his delight in an object is with him independent of interest, it is inevitable that he should look on the object as one containing a ground of delight for all men. For, since the delight is not based on any inclination of the Subject (or any other deliberate interest), but the Subject feels himself completely free in respect of the liking which he accords to the object, he can find as reason for his delight no personal conditions to which his own subjective self might alone be party (an die sich sein Subjekt allein hängte). Hence he must regard it as resting on what he may also presuppose in every other person; and therefore he must believe that he has reason for demanding a similar delight from every one. Accordingly he will speak of the beautiful as if beauty were a quality (Beschaffenheit) of the object and the judgement logical (forming a cognition of the Object by concepts of it); although it is only aesthetic, and contains merely a reference of the representation of the object to the Subject; - because it still bears this resemblance to the logical judgement, that it may be presupposed to be valid for all men (Kant, 1952: 50-51, § 6).

It is obvious that, here, common sense does not mean consensus. It is not a matter of proposing that the whole world will, in the end, agree to share the same assessment because the whole world applies a common criterion to everything - that would make aesthetic judgement become a determinant judgement again, and would therefore contradict everything that went before. The argument here is a lot more subtle because it is exclusively reflexive. There is nothing other than the delight that I feel in the presence of the object, nothing other than a subjective pleasure. And nothing else will intervene in what follows it: everything takes place in the domain of subjectivity. However, this is not an immobilized totality, an arrested identity: on the contrary it is a power of reflection. The above quote describes the process of this reflection: the delight felt by the subject is independent of his particular interest or any individual inclination; if I feel pleasure in front of this object it is not because it responds to a craving that I had prior to encountering it, that its presence then fulfils. The presentation of the objectisnot preceded by a will, ora desire, that would have rendered its presentation desirable or necessary. The object does not occur for my satisfaction, quite simply it occurs and it satisfies me by coming from elsewhere, from a region not previously circumscribed by me, independent of any predetermined end. The thing happens to me, it does not happen for me. And this is why it does not only occur to me. The delight that I feel is not the satisfaction of a craving or a will that would be mine exclusively. I am not satisfied because the thing responded to my expectations: in fact I did not have any expectation regarding it. Rather, it is that I am in the position of responding: I respond by feeling pleasure that will then be translated into the form of a judgement (of the type: "this thing is beautiful"), to the free presentation of something independent of all ends. This presentation is primary. And since it gives me pleasure, despite it being independent of my desires and my expectations, I can suppose that it will give others the same pleasure, and even that it will satisfy all others, since this pleasure will always be independent of the particular desires and expectations of individuals. 
Here, we need to pay special attention to the precision, and even at times to the apparent complication, of the expressions chosen by Kant. The subject, he writes, "must regard [his delight] as resting on what he may also presuppose in every other person; and therefore he must believe that he has reason for demanding a similar delight from every one" (Kant, 1952: 51). This "must" is not strictly speaking a constraint, but rather a kind of logical invitation; it is a concession, but one that sometimes, without taking anything away from its pleasure, introduces the subject to a distribution of its delight. The delight is founded, which is what the text says; it is preceded by a principle. This foundation is not in me; although this principle is subjective, it is not in me. It is in the relation that is established, without me willing it, between the presentation of the thing and the way that this presentation affects me. However, since I do not decide for myself the way in which it affects me, rather, it is the presentation itself that decides, I can "suppose" an affection, an identical reception in any other, and therefore "attribute" to all the others the delight that I felt from the presentation of this thing. These two verbs - to suppose and to attribute - complete the device of reflection: in the end something is projected, and it is only at that very moment, when I launch my pleasure beyond the strict limits of my individuality, that an operation takes place that is rigorously a judgement. I never judge alone: I judge when the I that judges expands to the dimensions of "every I"; when I am the one that will be able to be every I in the same situation. Therefore, the one who judges is common, and judgement proceeds from the community that is in me, that I shelter in some way and that I then liberate.

I liberate the community in me, since the delight that I feel from the presentation of something is not for my interest alone. Reflection is, in fact, a double movement: on the one hand, delight is strongly related to something (no pleasure without movement, without the relation of pleasure to something other than to itself, so it must in the end make an account, form a judgement). On the other hand, this first relation is projected (by attribution or supposition) onto other subjects. And, for the final projection to be possible, it is not enough - otherwise it would be the presupposed principal of complete explanation - that the delight be related to my interest alone, but be for the community that awakens in me. Since the pleasure is not related to me alone, it can be supposed to belong to all: as soon as there can be an effective relation of the delight, independent of an exclusively individual interest, this delight belongs, by right, to all. The negative (a pleasure exempt of interest) immediately converts into a positive (a shared pleasure), and judgement can take place (the formulation of the judgement: "this thing is beautiful" then has the form of an objective judgement. It seems to say something about the very thing itself, although it rests only on a subjective foundation. However, this foundation is really a principle, and the enunciated products that follow are really universals: as if the subjective universal of common sense spoke for itself, in a way that, in the objective form of the judgement, is both correct and illegitimate).

It is obvious that this way of understanding aesthetic judgement poses a formidable problem for architectural criticism. However, the way this difficulty is usually accounted for is, doubtless, insufficient. For example, when someone says, leaning heavily on the few passages in the Critique of Judgement that mention architecture, that the presentation of the architectural work, in contrast to the presentation of pictorial, musical or sculptural works, cannot be separated from interest and inclination, and is therefore unable to give rise to a disinterested delight in the 
subject, so architecture cannot be the occasion for this projection of the delight by which, as we saw, common sense expresses itself. The specifically architectural affect would always be too interested to correspond to the processes of aesthetic reflection as described by Kant, who, in fact, had to resort to other forms of art in order to describe it. And therefore the conclusion is: either a "Kantian" critique of architecture is possible, but it will never consider an architectural work to be a disinterested aesthetic presentation like a painting or a symphony, as an unforeseen event independent of any previously formulated end, but it will consider that which is not specifically architectural (the façade, or more generally the building reduced to its exterior representation, uninhabited we could say, literally, outside of its use); or else that criticism will treat architecture as such, but then it will only be able to account for its use, function, purpose, and its responding to a need, and therefore it will cease being "Kantian".

Not all of this is absolutely false. However, the fact remains that the architectural thing is no more reducible to $m y$ interest, to $m y$ inclination than any other artistic work. The delight that the presentation of an architectural work provokes in me is never just my delight alone, and the pleasure that I feel is no more immediate than the one that I feel when presented with a pictorial, musical or sculptural object. In other words, the architectural pleasure in me is also related to something else. If I say that a building is beautiful, that it is well conceived, that it responds to a need in a satisfactory way, I am doing something quite different from simply acknowledging an immediate feeling of well-being. I relate the pleasure that I feel to "something" in me, to that which is not exclusively me - this is, we discovered, the "definition" Kant gave for "disinterestedness". Since, concerning architectural presentation, we noted the effectiveness of the first moment of reflection - the rapport with or relation to - why should we deny ourselves the second moment - the projection, the supposition, the granting to "all the others" - and therefore the possibility of a judgement resting on a subjective principle?

This line of argument will, nonetheless, seem excessively sophistic: doesn't it try to rediscover a disinterestedness in architecture that is manifestly not found there? But we need to be more precise: it is not a matter of architecture in relation to itself, but the nature of the delight than it provokes (or doesn't) in us. We are not speaking here about a relation other than one which a subject maintains with the architectural thing, not of the thing itself. And, in fact, in this relation, we notice a movement that diverts the subject from the sole consideration of itself, or the sole experience without thinking about its affects. Why, then, do we continue to presuppose that this deviation, which is undisputable, is not entirely of same nature as the one at work when considering a musical or pictorial work? Because it is never disputed that the delight provoked by the architectural thing has even the smallest moment of "disinterestedness" (a moment when the subject does not keep this delight to himself, but relates it to something else), we cannot avoid presupposing that it is a matter of another type of disinterest from the one at work in music or painting. How then to think the difference between these types of disinterest?

At this point, we can risk the following hypothesis: the delight provoked by the architectural object would also be a relation to, but it would, nevertheless, not be possible to project it onto, "all others". Why? Not because this delight is too individual or too private, but on the contrary because, for architecture, the common 
is always too immediately present to be the object of a projection. For architecture, the community cannot be considered as the horizon of a supposition or an attributing to, because it is already present in the very presentation of the thing. The community here is not the object of a duty ("he must regard it as resting on what he may also presuppose in every other person"), for it is not ahead of, in the future of the subject, but already there in the very presentation. The common is not presumed, postulated, or supposed, it is in the presentation of the thing, in its very presupposition. And this is why the mechanism of reflection, to the extent that it experienced rapport and projection, cannot be effective: in architecture, from the outset, there is already what, in reflective judgement, had to be exhumed by the double movement of a suspension, and of an attributing to: the fact of the common in the presentation.

The difficulty would then be that, if the obviousness of the common prevents the judgement of architecture occurring with any precision, reflective judgement could no longer consist of the exposition of laws, rules or norms that would make architectural judgement a determinant judgement. The community is neither a need nor a concept: it is a fact. Architecture is the presentation of this fact. As such, architecture is not, or it is not exclusively, an aesthetic phenomenon, nor is it an object of science. Its evaluation is not exclusively related to either subjectiveuniversal principles upon which aesthetic delights are based, or objectiveuniversal principles upon which knowledge is constructed.

Thus, how can architectural criticism comprehend its own positivity, which, as hypothesised, is unavoidable, if this positivity cannot depend on any of these principles? Where will this criticism find its own legitimacy, if it cannot rest its judgements on one side or the other, and only ever misses its target when it tries to be artistic, just as much as when it tries to be scientific?

Obviously, these questions are not trying to invalidate architectural criticism. On the contrary, they show its inestimable interest, as an example of a discourse that is truly, constantly and constitutively confronted, in the very presentation of its object, by a necessary, and therefore unconstructible, presupposition of the fact of the community. Can we then suppose what its proper object will be if it is neither exclusively artistic nor exclusively scientific? From this point of view, what follows is only a tentative, hazardous and cautious attempt at a beginning. Let's suppose that architectural criticism relates to what, in architecture, proposes an experience of the fact that there is something in common. It would no longer be interested in architecture as a simple object, nor simply as an occasion for applying predetermined rules; rather, it would feel what, in architecture (in its visual aspects, certainly, but also in its use and in its potential for ethical and political invention in general), gives rise to, authorizes or emerges to open experience up to the presupposition of the common, and to evaluate - quite probably without any objective criteria - the particular quality of this invitation. ${ }^{4}$

Perhaps, something of this kind did try to emerge, at the end of Benjamin's famous text on the work of art, in the notion of a "tactile" reception distinguished from visual apprehension:

Buildings are appropriated in a twofold manner: by use and by perception - or rather, by touch and sight. Such appropriation cannot
4. Let us specify that this proposition is not only limited to collective architecture: there are individual constructions that inform the common from which they originate, just as there are, obviously and unfortunately, collective constructions that can destroy it, cover it over or to stifle it under pomposity or poverty. 


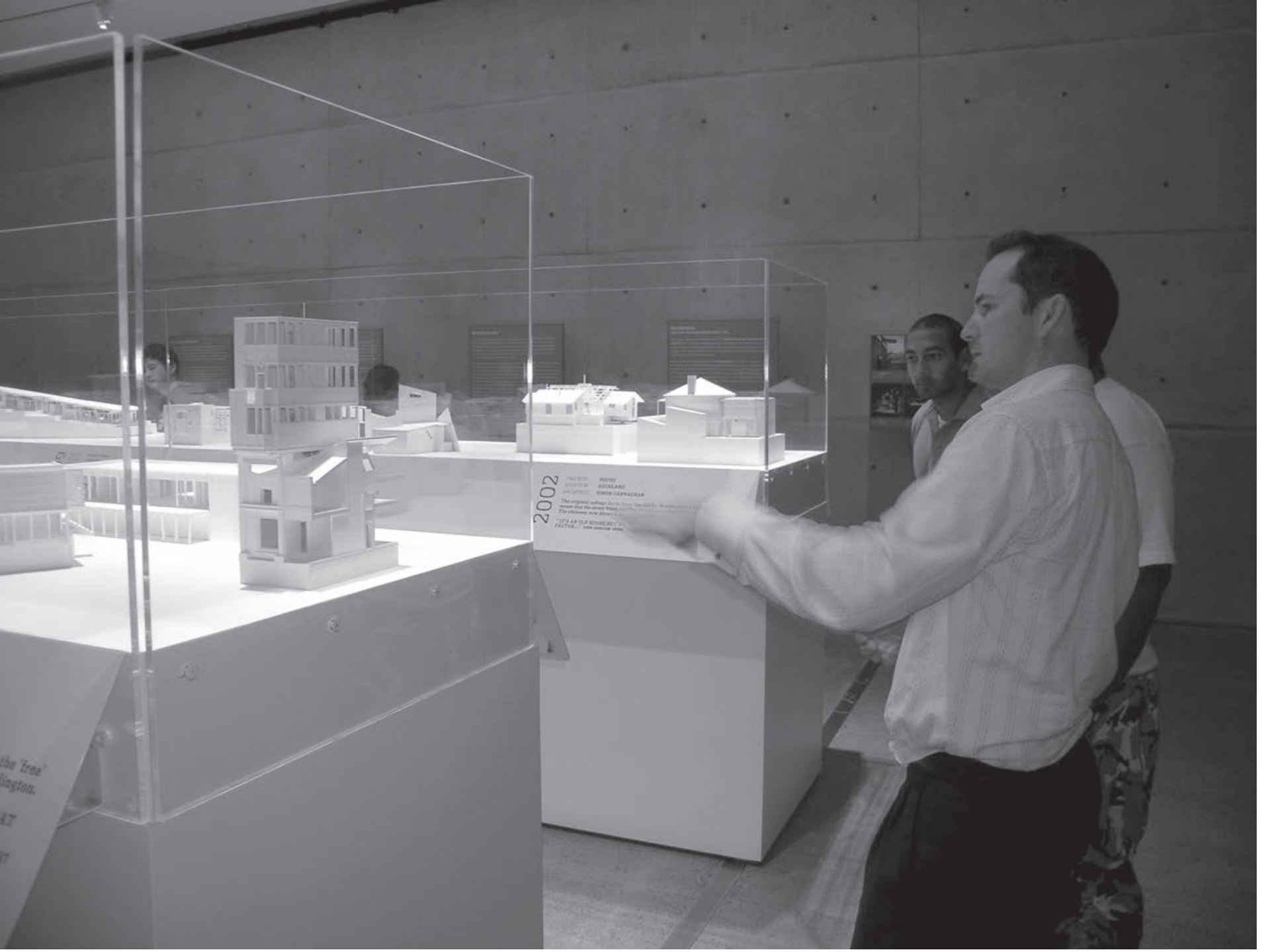

Criticizing architectural models: Tim Adams at Models for Living, 19052005, the Auckland Museum, 2005. Photograph by Elizabeth Cheng. be understood in terms of the attentive concentration of a tourist before a famous building. On the tactile side there is no counterpart to contemplation on the optical side. Tactile appropriation is accomplished not so much by attention as by habit. As regards architecture, habit determines to a large extent even optical reception. The latter, too, occurs much less through rapt attention than by noticing the object in incidental fashion (Benjamin, 1969: 240).

What is interesting about this distinction, which, by itself, can seem too simplistic and even naïve, becomes more apparent when we relate it to a remark made a little earlier in the text: that "architecture has always represented the prototype of a work of art, the reception of which is consummated by a collectivity in a state of distraction" (Benjamin, 1969: 240). Here, there is the indication of a solidarity between this kind of habitual, tactile, distracted reception and the experience of the community. This is not something that can be felt with the effort of attention, with the concentration and contemplation that corresponds more to an individual experience. The common is not what we place in front of ourselves, like an isolated object to be examined at our leisure, but it is what we are in, to which we belong before we have even made the decision to examine it. And, perhaps, this is the reason why architecture is such an experience of the common. In contrast to what happens, for example, with a picture, the reception that we give to a building does not consist of placing it in front of us as something separate. Here, the experience takes place precisely without placing the object at a certain distance in order to make it have an effect, without any defining or delimiting it. We are in the building, we touch it and are touched by it in a dimension of participation or, better, of com-motion: we move together without 
ever being able to grasp, by ourselves, what the building is in its entirety. Even the powers of representation, by which I could assure myself of my mastery over the building, are insufficient here: architecture, as such, having spaces that can be traversed and divided, is always beyond its image. We cannot isolate it as we do when framing a picture to be mounted on a wall and later appreciated. We are in architecture even before we notice it; before we decide to observe it, it has already proposed itself to us and we are already affected according to our least reflective and least analytical sensibilities. We move ourselves in it, and it delivers itself to us according to such displacements, as an inseparably spatial and temporal suggestion: a com-motion that would therefore need to take into consideration the fact that this suggestion immediately addresses itself to a plurality, not just to a singularity. The only architecture is one that is distributed, since it can only authorize a multiplicity of journeys. Each one of these journeys is a collective adventure: an experience of the community in so far as it is not constructed like a work, in so far as it is not reducible to a body of laws that could be enunciated $a$ priori. It is already there, experienced in the variety of journeys and the necessarily divided character of each one. It is never presented truthfully by itself, never figured in a illustrative or exemplary manner (except in architectural publicity, but even then things are not as simple as they seem); it is what can be experienced in its presentation - even if the presentation itself contradicts this experience, instead of supporting it.

Benjamin then adds an obviously essential remark about this absent-minded tactile reception:

This mode of appropriation, developed with reference to architecture, in certain circumstances acquires canonical value. For tasks which face the human apparatus of perception at the turning points of history cannot be solved by optical means, that is by contemplation alone. They are mastered gradually by habit, under the guidance of tactile appropriation (Benjamin, 1969: 240).

This wastosuggest someimportant issues about architectureand that we should take responsibility for them. The text was written in 1936. The question of knowing what could be made from a presupposition of community in architectural presentation was then a burning issue. Are things qualitatively any different today? Is the idea that architectural criticism should again confront such questions only a ridiculous anachronism or, on the contrary, is it necessary to assert that it has to if it is to participate in a very necessary resistance?

\section{References:}

Baudelaire, C. (1992). The Salon of 1846. In Charles Baudelaire: Selected Writings on Art and Literature (P. E. Charvet, Trans.). Harmondsworth: Penguin Books.

Benjamin, W. (1969). The Work of Art in the Age of Mechanical Reproduction. In Arendt, H. (Ed.). Walter Benjamin, Illuminations (H. Zohn, Trans.). New York: Schocken Books.

Kant, E. (1952). Introduction. In The Critique of Judgement (J. C. Meredith, Trans.). Oxford: Oxford University Press. 